ИЗВЕСТИЯ АКАДЕМИИ НАУК ЭСТОНСКОИ ССР. ТОМ 29 Химия. 1980, № 2

В. МИХКЕЛЬСОН, А. КЫБУ, О. ЭИЗЕН

\title{
ИССЛЕДОВАНИЕ РАБОТЫ КОЛОНКИ С ЩЕТОЧНЫМ РОТОРОМ
}

Известно ['], что роторные колонки с щетками обладают существенным преимуществом перед колонками с гладким ротором, так как здесь поверхность жидкой пленки непрерывно обновляется, что заметно ускоряет процесс массообмена.

В настоящее время практическое применение находят колонки с вращающейся лентой, которые можно также отнести к категории колонок с щеточным ротором, так как лента касается стенок и размазывает, как и щетки, жидкую фазу по стенке, обеспечивая непрерывное обновление поверхности массообмена. По техническим соображениям ленточные колонки изготовляют малого диаметра, и, следовательно, они имеют малую производительность. Изготовление более производительных колонок с ротором с щетками связано с определенными трудностями, вследствие чего до настоящего времени они не получили распространения. В Институте химии АН Эстонской ССР удалось разрешить основные затруднения, и здесь была сконструирована и изготовлена вакуумная колонка с щеточным ротором.*

В настоящей статье приведены данные по иопытанию названной колонки. Колонка с внутренним диаметром 28 мм снабжена ротором длиною 440 мм и диаметром 22 мм с 640 усиками, составляющими щетку. Колонка изготовлена из стекла и фторопласта-4. Максимальная рабочая температура колонки ограничена свойствами фторопласта и составляет $\approx 170^{\circ} \mathrm{C}$.

Предварительными опытами установлено, что эффективность колонки зависит от скорости вращения ротора. При скорости вращения 1800 об/мин и меньше эффективность падает. При испытанных скоростях 2000 - 3000 об/мин эффективность постоянна. В качестве рабочей была избрана скорость 2400 об/мин.

\section{Экспериментальная часть}

Определение перепада давления. В куб колонки был залит этилбензол и установлен водяной манометр. При установившемся режиме кипения этилбензола делался отсчет по манометру и затем отбирался весь конденсат в мерный цилиндр (определение времени отбора по секундометру). По этим данным определялась скорость испарения. При максимальной производительности куба $1700 \mathrm{\mu л/ч} \mathrm{(на} \mathrm{пределе} \mathrm{«захлебывания»)}$ перепад давления составил 9 мм вод. $c т$, а при 300 мл/ч $-2,5$ мм вод. ст.

* Детальное описание этой колонки будет дано в отдельной статье.

3 ENSV TA Toimetised. K 21980 
Определение общей рабочей задержки. В сухую ректификацнонную установку мерным цилиндром заливалось точно 50 мл этилбензола. При установившемся режиме быстро отбирался дистиллят, пока на дне колбы не кончалась жидкость. Разность между количеством взятого этилбензола и количеством полученного дистиллята и есть общая рабочая задержка. Общая задержка установки составляет около 4 мл и мало зависит от производительности куба.

Определение эффективности. Эффективность колонки определялась, как обычно, прн полном возврате флегмы. При выбранной производительности куба колонке давали выйти в режим и через полчаса отбирали небольшую пробу, а с интервалом 15 мин еще две пробы. Первую пробу отбрасывали как непредставительную, а следующие две анализировали на содержание компонентов. Изменяя производительность куба, опыт повторяли. В вакууме, при остаточном давлении 100 мм рт. ст., опыты ставилигь аналогично.

Определения проводились со смесью этилбензол-м-ксилол (разность температур кипения $\left.3,1^{\circ}\right)$. Исходная смесь содержала около 0,4 мольных долей этилбензола. Компоненты смеси с чистотой не менее $99,95 \%$ приготовляли очисткой реактивов марки «ч» путем азеотропной ректификации с метилцеллозольвом и многократной ректификации на исследуемой колонке.

Чистоту исходных компонентов, состав кубовой жидкости и состав отобранных фракций определяли на газовом хроматографе Хром-4 (ЧССР) с капиллярной колонкой длиною $50 \mathrm{M}$ со скваланом при температуре $100^{\circ}$ (ионно-пламенный детектор).

\section{Обсуждение результатов}

Как и следовало ожидать, перепад давления в колонке очень невелик. Малому перепаду давления способствуют как большое свободное сечение колонки $\left(2,4 c M^{2}\right)$, так и щетки, при работе которых исключается «зависание» флегмы в колонке. Перепад давления в вакууме не изучался, полагая, что он может быть легко рассчитан из полученных данных по известным гидродинамическим соотношениям.

Задержка установки оказалась незначительной. Она распределяется на задержку в головке, в колонке и на стенках куба (ротор колонки отбрасывает флегму на стенки куба). Трудно оценить, сколько жидкой фазы в каждой части установки, но даже если считать, что вся флегма распределена на стенке колонки, то получится, что толщина жидкой пленки составляет $\approx 0,1$ мм.

Тот факт, что задержка практицески не зависит от производительности куба, доказывает, что работа

Эффективность роторной вакуумной колонки с щетками при различных режимах

\begin{tabular}{c|c|c}
\hline \multicolumn{2}{c|}{ Режнм } & Высота, \\
\hline $\begin{array}{c}\text { Давле- } \\
\text { ние, }\end{array}$ & Скорость & эквива- \\
испарения & лентная \\
рт. ст. & в кубе, мл/ч & ТТ \\
\hline
\end{tabular}

$\begin{array}{lcc}760 & 70 & 1,2 \\ 760 & 100-200 & 1,2 \\ 760 & 700-800 & 1,8 \\ 760 & 1700 & 3,4 \\ 100 & 50 & 1,9 \\ 100 & 200 & 5,0 \\ 100 & 500 & 7,7\end{array}$
щеток препятствует зависанию жидкости в колонке.

Нужно полагать, что ротор колонки практически сухой, так как жидкость сбрасывается с него центробежной силой.

Выбранная нами для определения эффективности смесь этилбензолм-ксилол ведет себя практически как идеальная (компоненты по структуре одинаковы). Вместе с тем, определение состава таких смесей с близкими свойствами, как этилбензол-м-ксилол, на современных прецизионных газовых хроматографах не представ- 
ляет затруднений. Преимуществом выбранной смеси является возможность определения эффективности как при атмосферном, так и при пониженном давлении.

Данные по эффективности (в ТТ), приведенные в таблице, рассчитаны по формуле Фенске

$$
\alpha^{(N+1)}=\frac{C_{\mathrm{r}}\left(1-C_{\mathrm{K}}\right)}{C_{\mathrm{K}}\left(1-C_{\mathrm{r}}\right)},
$$

где $\boldsymbol{\alpha}$ - относительная летучесть; $N$ - число ТТ; $C_{\mathrm{r}}$ и $C_{\mathrm{K}}$ - концентра. ция легколетучего компонента, соответственно в головке и кубе (в мольных долях).

Концентрация компонентов $\left(C_{\mathrm{r}}, C_{\mathrm{K}}\right)$ была установлена экспериментально (см. выше). Относительная летучесть рассчитана по данным $\left[{ }^{2}\right]$ по формуле

$$
\alpha=\frac{P_{t}^{\ni Б}}{P_{t}^{\mathrm{MK}}}
$$

Давление компонентов определено по формуле Антуана

$$
\lg P=A-\frac{B}{C+t} \text {. }
$$

(Константы уравнения Антуана для этилбензола: $A=6,95719 ; \quad B=$ $=1424,255 ; \quad C=813,206 ; \quad$ для $\quad$-ксилола: $A=7,00908 ; \quad B=1462,266$; $C=215,105$.)

Практически по температуре экоперимента рассчитывают давлениє паров чистых компонентов по формуле (3), затем $\alpha$ по формуле (2) и наконец, $N$ по формуле (1).

Данные таблицы показывают, что колонка обладает высокой эффективностью, которая уменьшается с увеличением производительности. В вакууме эффективность несколько меньше.

\section{Выводы}

1. Установлено, что основные характеристики (эффективность, малая задержка, малый перепад давления) роторной колонки с щетками столь же высоки, как у лучших образцов современных колонок с вращающейся лентой, но производительность значительно выше.

2. Для определения эффективности колонки впервые предложена смесь этилбензол-м-ксилол с практически идеальным поведением, дающая возможность рассчитывать относительную летучесть по давлению паров чистых компонентов. Это позволяет объективно сравнивать работу колонки при разных давлениях, так как здесь учитывается изменение относительной летучести с температурой.

3. Вследствие высоких эксплуатационных качеств испытанная колонка подходит для исследования свойств азеотропных растворов с максимальным давлением паров. 
Л ИТ Р РАТ У РА

1. К рель Э. Руководство по лабораторной ректификации. М., 1960.

2. Handbook of vapor pressures and heats of vaporization of hydrocarbons and related compounds. Texas, 1971.

Ннститут химии

Академии наук Эстонской ССР

Поступила в редакцию

28/V 1979

V. MIHKELSON, A. KOBU, O. EISEN

\section{ROTEERUVA HARJASSODAMIKUGA KOLONNI UURIMINE}

Artiklis on kirjeldatud harjassüdamikuga rektifikatsioonikolonni uurimise tulemusi. Kolonni iäbimõōt on $28 \mathrm{~mm}, 640$ harjasega rootori pikkus $440 \mathrm{~mm}$, läbimõõt $22 \mathrm{~mm}$, pöörlemiskiirus $2400 \mathrm{p} / \mathrm{min}$; materjalid teflon ja klaas.

Uuriti rõhulangu, flegmasisalduse ja efektiivsuse sõltuvust tootlikkusest atmosfäärirōhul ja vaakuumis (jääkrōhk $100 \mathrm{~mm} \mathrm{Hg}$ ). Efektiivsusandmed on esitatud tabelis 1 . Flegmasisaldus on $c a 4 \mathrm{ml}$, see sõltub tootlikkusest vähe. Rõhulang uppumispiiril on $9 \mathrm{~mm} \mathrm{H} \mathrm{H}_{2} \mathrm{O}$ ja tootlikkuse juures $300 \mathrm{ml} / \mathrm{h} 2,5 \mathrm{~mm} \mathrm{H} \mathrm{H}_{2} \mathrm{O}$.

\section{MIHKELSON, A. KOBU, O. EISEN}

\section{INVESTIGATION OF BRISTLE-ROTOR DISTILLATION COLUMN}

In the present paper the working conditions and results of bristle-rotor distillation column have been described. The diameter of this column is $28 \mathrm{~mm}$; length of the bristle-rotor with 640 bristles is $440 \mathrm{~mm}$ and diameter $22 \mathrm{~mm}$. Rotor speed was set up to $2400 \mathrm{rpm}$. As construction materials glass and teflon were used.

The pressure drop, hold-up and efficiency of the column were determined at atmospheric pressure and in vacuum at pressure adjusted to $100 \mathrm{~mm}$ of $\mathrm{Hg}$. The results of the efficiency of the column obtained are presented in tabular form (Table). Total hold-up of distillation run had a value of about $4 \mathrm{ml}$. It does not depend much on the boil-up rate. At conditions near to flooding the pressure drop was $2 \mathrm{~mm}$ of $\mathrm{H}_{2} \mathrm{O}$ and at the boil-up rate, $300 \mathrm{ml} / \mathrm{h}$, was $2.5 \mathrm{~mm}$ of $\mathrm{H}_{2} \mathrm{O}$. 